\title{
Nueva edición del ensayo Guatemala (Editorial Cultura, 2018) de José Martí
}

A new edition of José Martís Essay, Guatemala Uma nova edição do ensaio de José Martí, Guatemala

La pieza Guatemala, escrita por el poeta y patriota cubano José Martí, constituye su visión del país centroamericano que lo acogió como a un hijo durante una estancia de aproximadamente un año y medio a partir de $1877 . \mathrm{Su}$ discurso se detiene, no solo en las condiciones sociopolíticas y culturales de la región a finales del siglo XIX, sino que describe su vigorosa y peculiar geografía, repasa su composición étnica, caracteriza a sus creadores y vislumbra un futuro

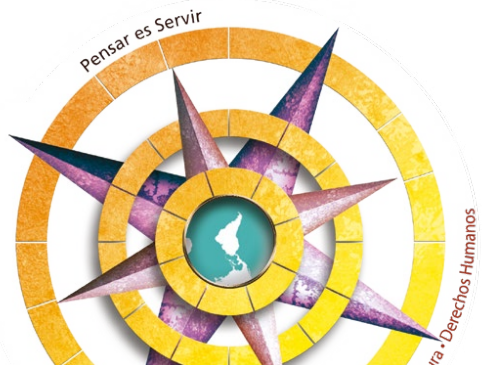
malteca desde la perspectiva de un viajero observador y reflexivo vuelve al público lector, ahora, en el año 2018, gracias a la editorial Cultura, del Ministerio de Cultura y Deportes de Guatemala. Esta institución tiene como horizonte esencial la publicación y promoción de la creación nacional de todas las épocas, estilos, tendencias y generaciones. Solo publica autores foráneos en su colección homenaje. 
Precisamente, a propósito del aniversario 140 de la estancia de José Martí en la tierra del quetzal, la editorial Cultura preparó una nueva entrega de su ensayo Guatemala. En esta ocasión, el texto, en edición crítica, se brinda con un esclarecedor prólogo del historiador Pedro Pablo Rodríguez, un cuerpo de notas al pie, el cual no solo establece el texto original, sino que también ofrece un aparato referencial que apoya y esclarece su lectura. Complementan la propuesta dos valiosos índices: geográfico y de nombres. En este último predominan personalidades guatemaltecas, como es de suponer; pero se extiende también a creadores célebres de Latinoamérica y Europa. Súmese a ello que las portadillas del volumen brindan una síntesis biográfica de José Martí, muy útil para los nuevos lectores que se acercan a descubrir el universo martiano.

Es la segunda edición guatemalteca del ensayo. Antes tuvo una auspiciada por la Universidad San Carlos de Guatemala. También ha tenido dos experiencias editoriales en $\mathrm{Cuba}^{1}$ como texto independiente; pero, realmente, esta investigación forma parte de la Edición Crítica de las

1 José Martí: Guatemala (Edic. crítica de Pedro Pablo Rodríguez y María Talavera), Centro de Estudios Martianos y Editorial José Martí, La Habana, 1998. Tuvo otra edición posterior.
Obras Completas de José Martí que realiza el Centro de Estudios Martianos de La Habana desde hace más de dos décadas. ${ }^{2}$

La llegada de José Martí a Guatemala a través de la vía Livingston-Izabal-Zacapa fue la primera experiencia que tuvo para adentrarse no solo en la geografía del país sino también en sus complejidades étnicas. El viajero venía procedente de México, donde tenía compromiso de matrimonio con la joven cubana Carmen Zayas Bazán. Meses después regresa a México; pero por la vía del océano Pacífico, es decir, a través del puerto de San José y llega a tierra azteca por la zona de Acapulco. Este recorrido lo hace a la inversa con su esposa semanas más tarde. Es la posibilidad de conocer otras aristas profundas de la naturaleza y la cultura de la tierra de Miguel Ángel Asturias.

Martí va describiendo cada una de las ciudades por donde transita y las caracteriza desde las aristas que más le llaman la atención: repara en sus valles, su agricultura, su arquitectura, sus fiestas tradicionales, sus platos típicos, su creación artística. Todas estas vivencias le sirvieron de fuente para la elaboración de su

2 José Martí. Obras completas. Edición crítica, t. 5, Centro de Estudios Martianos, La Habana, 2009, pp. 235-287.

130 Nueva edición del ensayo Guatemala (Editorial Cultura, 2018) de José Martí Mauricio Núñez-Rodríguez 
ensayo, al que le imprime un estilo narrativo rápido, vertiginoso, trepidante. Quiere brindar la mayor cantidad de información en el menor tiempo y espacio posible. El ritmo está muy relacionado con la manera en que la escribe. Es de las escrituras "al paso" de José Martí. Él mismo lo expresa en un momento del discurso: "estas páginas tan rapidísimas, casi escritas entre los cerros y a caballo". Pero, a pesar de ello, la madurez y agudeza crítica alcanzada por el poeta está expresada en sus páginas. Por ejemplo, numerosos de sus pensamientos esenciales sobre la educación aparecen aquí: "Saber leer es saber andar. Saber escribir es saber ascender" o aquella idea de que "Hombres recogerá quien siembra escuelas". Estas líneas fueron útiles para Guatemala y Centroamérica, pero también para el Caribe y el resto del continente latinoamericano.

Además de su conocido poema IX de Versos sencillos dedicado a La niña de Guatemala, otras piezas encierran rasgos de sus vivencias por estas cálidas regiones centroamericanas. Algunas se detienen explícitamente en el universo guatemalteco, como, por ejemplo: su Diario de Izabal a Zacapa, la pieza Patria y Libertad (Drama indio), el epistolario redactado durante su estancia; mientras que en otras ocasiones -como sucede en su única novela Lucía Jerez- parece ser que recrea zonas de su geografía y cultura. Esta presencia múltiple expresa la importancia de Guatemala en la vida, la obra y el pensamiento de José Martí.

Esta edición se distingue, sobre todo, por el notable prólogo del conocido historiador Pedro Pablo Rodríguez que integra la estancia guatemalteca de José Martí al proceso de crecimiento y consolidación de su madurez nuestramericana. Su estudio no solo se detiene en la estancia en el país, sino que analiza los antecedentes de su anterior vivencia en México y el destino posterior del autor. Particulariza, como rasgo inseparable para comprender cabalmente sus reacciones y decisiones, las complejas peculiaridades del contexto sociopolítico y cultural al que asiste el poeta en aquellos días.

Martín Díaz Valdés fue el artista guatemalteco que se encargó del diseño de portada e interior del volumen y el poeta Francisco Morales Santos, Premio Nacional de Literatura Guatemalteca "Miguel Ángel Asturias" y director de la editorial Cultura, ha sido el gestor del homenaje al Apóstol cubano.

Las palabras de Carlos de Céspedes Piedra, embajador de la República de 
Cuba en Guatemala y de Héctor Iván Espinoza Farfán, embajador de la República de Guatemala en La Habana, anteceden esta edición conmemorativa como expresión de un proceso de trabajo en equipo, desde ambos países, a propósito de este aniversario del paso de Martí por Guatemala.

Volver a publicar esta significativa pieza de José Martí es regresar sobre sus pasos por Centroamérica, una región esencial en su vida, madurez y crecimiento intelectual. Es una expresión de los entrañables lazos históricos y culturales que unen al Caribe y Centroamérica, a Cuba y a Guatemala. Un diálogo que continuó en el siglo XX y, por esa necesidad de los pueblos de conocerse, perdura y se enriquece en la contemporaneidad. 